\title{
Research on Modes and Defiance of Big Data and Cloud Computing
}

\author{
Manish Bhardwaj* and Arti Sharma \\ KIET Groups of Institutions, Computer Science and Engineering, India \\ ${ }^{*}$ Corresponding author
}

\begin{abstract}
Huge data is presently one among the foremost basic rising advances. vast information area unit used as an inspiration that alludes to the failure of customary data structures to proficiently upset the new informational indexes. The 4V's of huge statistics - volume, speed, assortment \& truthfulness define the executives $\&$ investigation attempting for the standard information distribution centers. It's imperative to contemplate bigdata and examination along. The coordinative vast data with distributed computing advances, organizations and instruction foundations will have a superior course to what is to come back. In any case, there's an enormous concern with reference to protection and security problems once moving to the cloud that is that the elementary driver concerning why organizations and instructive foundations will not budge to the cloud. This manuscript presents attributes, patterns and difficulties of huge statistics. In this case, it researches the remuneration and it also provides the dangers that will ascend absent of the coordination among vast statistics and distributed computing.
\end{abstract}

Keywords-map reduce; Iaas; Paas; SaaS; cloud computing

\section{INTRODUCTION}

Enormous information is associate degree info examination system authorised by another age of innovations and style that bolster high-speed info catch, reposition, and investigation. info sources stretch out past the customary company info to include email, telephone yield, sensorproduced info, and web-based social networking yield [1]. info square measure nevermore restricted to organized info records but incorporate unstructured info - info having no customary composition [2].

Huge information needs prodigious measures of additional area. whereas the price of capability unbroken on declining, the assets expected to use vast info will even currently gift cash connected challenges for small to medium measured organizations. an everyday huge info reposition and examination framework are based on clustered prepare joined capability (NAS). clustered NAS framework needs setup of a couple of NAS "cases" with each na "case" contained a couple of reposition gizmos related to a NAS gadget. The arrangement of NAS gadgets square measure then unified to permit mammoth allocation and looking out of statistics[3].

Distributed computing is associate degree improbably effective worldview of administration placed registering, and has upset the way within which process framework is disconnected and used. 3 most thought cloud standards include: Infrastructure as a Service (IaaS), Platform as a Service (PaaS), and package as a Service (SaaS). the concept anyway will likewise be reached bent info as a Service or Storage as a Service. skillfulness, pay-examine, low forthright speculation, low time to plug, associate degreed move of dangers square measure some of the most important empowering highlights that create distributed computing an all inclusive worldview for conveyance novel applications which weren't financially potential in an exceedingly customary endeavor framework settings.

The paper is sorted out as pursues: in area 2, Introduction about the topic is given. Area 3 demonstrates the general Overview of the Big data. Section 4 of this manuscript describes the overview of management of dynamic information in CLOUD. In segment five, we tend to gift the "Map Reduce" and "Hadoop" a free indoctrination composition underpins the handling of huge provision of statistics in an exceedingly distributed registering condition. The paper at long last finished up in space 6.

\section{RELATED WORK}

Huge knowledge and Cloud process square measure an interesting patterns that square measure quickly was developing and new difficulties and arrangements square measure being distributed on a daily basis. In 2014, a production was created to characterize the most effective techniques to send large information examination details to the cloud[4]. Some arrangement of stepladder square measure characterized in half-dozen stages: the most stage, we tend to build up the commerce use crate by concentrating on however the profound trade esteems are going to be accomplished by shifting to the cloud \& acknowledge the processing tools to accomplish. Following this is often adjusting the partner's stipulations to the crate therefore on accomplish their facilitate. At long last the case should be plausible by recognizing the key favorable circumstances that out weight totally different arrangements accessible; the following stage, is to induce to you application outstanding burden. Contingent upon the sensible necessities put and trade crate, the cloud administration have to be compelled to have to be compelled to the capability to assist the remaining task at hand with the capability to quickly enhance because the new outstanding tasks at hand return on the web[5]; The third organize, is to make up a specialised thanks to traumatize the massive info 
stage by concentrating with each Analysis situs and knowledge stages; The 4 point is to deal with administration, shield, protection, hazard and responsibility stipulations.

In Next Manuscript distributed on the reconciliation of monumental info and distributed computing advancements[6]. In connection of vast info and distributed computing have vast benefits of the two bits of information and execution. attributable to the loads of knowledge gathered, they need to examined usually the data is futile; therefore the cloud administrations will traumatize these broad measures of knowledge with quick reaction times and constant handling of the data. There square measure at this time some of coordinated cloud things for large info examination; Canpaas may be a domain created by Vrije Universiteit Amsterdam.

In this manuscript author describe the proficiency of monumental info and distributed process computing and why the 2 advancements supplement each other. large info and distributed computing supplement one another and square measure each the fastest developing advances rising nowadays[7]. The cloud looks to offer hefty registering authority by amassing assets along and providing a solitary framework read to traumatize these assets and applications, therefore why large info have to be compelled to be attack the cloud? The attendant reasons provide Associate in Nursing adequate response to the inquiry shut by: value decrease, wherever associations will utilize the payper utilize model as opposed to doing an interesting venture to arrangement servers and bunches to traumatize the large information.

\section{GENERAL OVERVIEW OF BIg DATA}

Huge information square measure used as a thought that alludes to the impotence of standard data styles to effectively modify the new informational collections. Attributes that power another engineering to accomplish efficiencies square measure the informational index terribly still qualities volume, and assortment of data from various areas or types; and from the data moving attributes of speed, or pace of flow, and inconstancy (mainly alluding to AN adjustment in speed) [8]. each one of those qualities brings concerning varied models or varied data lifecycle method orderings to accomplish needed efficiencies. varied totally different terms (frequently starting with the letter ' $V$ ') square measure to boot used, nevertheless a amount to touch of the examination and not monumental statistics models, as appeared in Figure one.

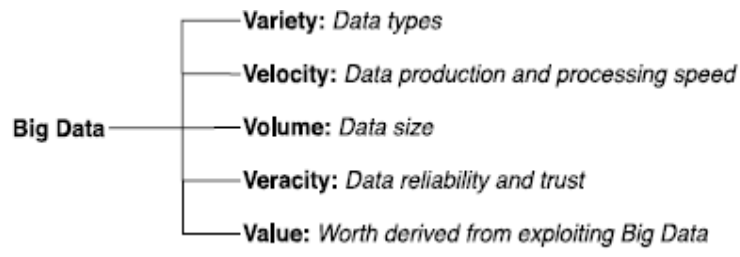

FIGURE I. V'S OF BIG DATA

\section{MANAGEMENT OF DYNAMIC INFORMATION IN CLOUD}

An info the board framework has totally different phases of data lifecycle, for instance, info bodily process, separate amendment load (ETL), info making ready, info chronicled, and erasure. Before moving at least one phases of data lifecycle to the cloud, one has to consider the attendant components:

1. Accessibility Guarantees: every distributed computing provider will guarantee a particular live of accessibility ensures Value-based info handling needs brisk in progress answers whereas for info distribution centers long running inquiries area unit utilised to provide reports.

2. Unwavering quality of Cloud Services: Before offloading info the board to cloud, undertakings have to be compelled to guarantee that the cloud provides needed degree of reliableness to the knowledge administrations.

3. Security: information that's sure by severe protection tips, for instance, therapeutic information secured by the insurance movability and responsibleness Act (HIPAA), can necessitate that shoppers register to be directed to their safe info server.

4. Practicality: info organization is AN exceptionally proficient movement which has selecting however info have to be compelled to be sorted out, that files and views have to be compelled to be preserved, so forth. One has to painstakingly assess whether or not of these repairs tasks is performed over the cloud info.

5 Manage huge information in Cloud Computing Environments: Cloud Computing could be a scenario obsessed on utilizing and giving administrations. There area unit numerous categories during which the administration organized frameworks is bunched. one amongst the foremost utilised path to assemble that frameworks the reflection point that's accessible to the framework shopper. on these lines, 3 distinct levels area unit frequently recognized: Infrastructure as a Service (IaaS), Platform as a Service (PaaS), and computer code as a Service (SaaS) as appeared in Figure 2.

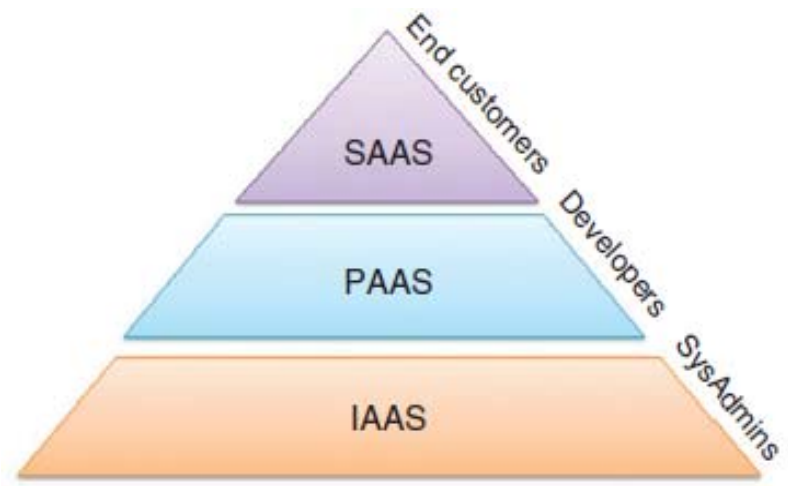

FIGURE II. SERVICE ORIENTED COMPUTING LAYERS

One key angle in giving execution to huge information examination applications is that the info region. this is often on the grounds that the quantity of data engaged with the examination makes it restrictive to maneuver the knowledge to method it. 


\section{CONCLUSION}

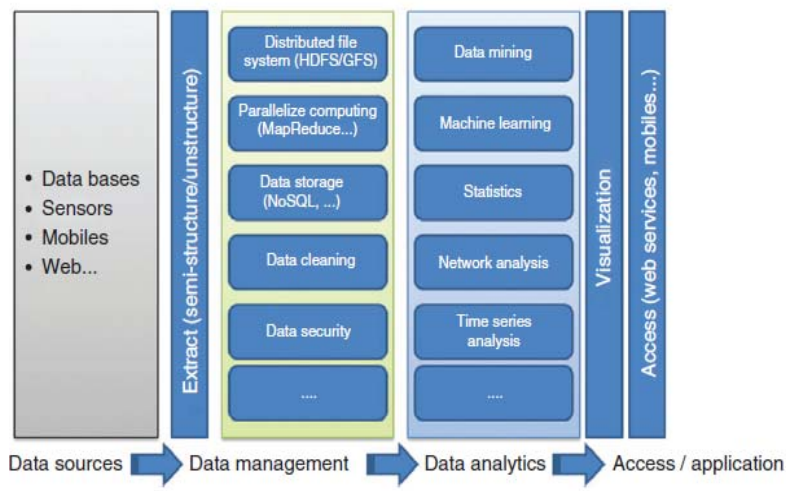

FIGURE III. FRAMEWORK OF BIG DATA

\section{Resource Management and Data Processing}

When creating an endeavor to recognize the perception of massive knowledge, the expressions, as an example, "Guide Reduce" and "Hadoop" cannot be dodged.

\section{A. Hadoop}

Hadoop, could likewise be a liberated Java oriented programming framework help in the treatment of monster game plans of statistics terribly condition. This is a tad of the Apache assignment upheld by the Apache bundle organization. Hadoop bundle uses a top down structure. Using Hadoop, enormous educational files could likewise be taken care of over a gaggle of servers and applications could likewise be whole running on structures with a good numerous center points together with a huge differ of terabytes. conveyed record method in Hadoop helps in quick statistics move charge and with permission the structure to persist with its conventional action yet because of some center point dissatisfactions. this technique cuts down the threat of an intact structure disillusionment, yet by virtue of endless center point dissatisfactions.

\section{B. Map Scale Back}

Hadoop Map scale back might be a framework acclimated form applications that strategy huge volume of information in comparable on lots of product instrumentation assets in a strong, insufficiency liberal methodology. A Map scale back work beginning isolates the data into individual things that square measure prepared by Map livelihoods in comparable. The yields of the maps resolve out by the scaffold square measure then commitment to the diminishing endeavors.

\section{Hadoop Distributed Filling System}

HDFS might be a record structure that navigates the majority of the centers in a very Hadoop bunch for information stockpiling. It associates along report systems on neighborhood center points to make it into one tremendous record structure. HDFS improves dependableness by continuation information over fluctuated sources to beat center disillusionments.
Enormous data is correct currently one among the foremost basic rising advances. The 4 main point of huge data - amount, speed, assortment and truthfulness obtain the knowledge the executives and examination making an attempt for the conventional data distribution centers. Distributed computing is by all accounts a perfect vehicle for facilitating monumental data remaining tasks at hand. Be that because it could, breaking away at large data within the cloud brings its own take a look at of accommodating 2 opposing structure standards. The incorporating large data with distributed computing advances, organizations and coaching institutions will have a superior course to what's to return. The paper introduced the final concepts and which means of massive information, and showed the event of data the executives to distributed computing. This manuscript introduced the "Map Reduce" \& "Hadoop" as huge information frameworks that facilitate the handling of big arrangements of data in a very spread problem solving condition. This paper in addition bestowed the qualities, patterns and difficulties of monumental data. Notwithstanding that, it researches the benefits and therefore the dangers which will ascend out of the mix between monumental data and distributed computing. the numerous little bit of leeway that gives distributed computing and large statistics combination is that the records repositing and making ready authority accessibility, the cloud approaches a massive pool of assets and differing types of foundations that may suit.

\section{REFERENCES}

[1] R. L. Villars, C. W. Olofson, \& M. Eastwood, Big data: What it is and why you should care. IDC White Paper. Framingham, MA: IDC, 2011.

[2] C. Coronel, S. Morris, \& P. Rob, Database Systems: Design, Implementation, and Management, (10th. Ed.). Boston: Cengage Learning, 2013.

[3] C. White, C, Data Communications and Computer Networks: A business user's approach, (6th ed.). Boston: Cengage Learning, 2011.

[4] IOS Press. Guidelines on security and privacy in public cloud computing. Journal of EGovernance,34 149-151. DOI: 10.3233/GOV-2011-0271, 2011.

[5] J. B. Rothnie Jr., P. A. Bernstein, S. Fox, N. Goodman, M. Hammer, T. A. Landers, C. L. Reeve, D. W. Shipman, and E. Wong. Introduction to a System for Distributed Databases (SDD-1). ACM Trans. Database Syst., 5(1):1-17, 1980. https://doi.org/10.1145/320128.320129

[6] J. Dewitt, S. Ghandeharizadeh, D. A. Schneider, A. Bricker, H. I. Hsiao, and R. Rasmussen. The Gamma Database Machine Project. IEEE Trans. on Knowl. and Data Eng., 2(1):44-62, 1990. https://doi.org/10.1109/69.50905

[7] J. Chang, S. Dean, S. Ghemawat, W. C. Hsieh, D. A. Wallach, M. Burrows, T. Chandra, A. Fikes, and R. E. Gruber. Bigtable: A Distributed Storage System for Structured Data. In OSDI, pages205-218, 2006.

[8] Dean and S. Ghemawat. MapReduce: simplified data processing on large clusters. In OSDI, pages 137-150, 2004.

[9] Apache Hadoop Project. http://hadoop.apache.org/core/, 2009

[10] Thusoo, J. S. Sarma, N. Jain, Z. Shao, P. Chakka, S. Anthony, H. Liu, P. Wyckoff, and R. Murthy. Hive - A Warehousing Solution Over a MapReduce Framework. PVLDB, 2(2):1626-1629, 2009

[11] R. Gupta, H. Gupta, and M. Mohania, "Cloud Computing and Big Data Analytics: What Is New from Databases Perspective?". S. Srinivasa and V. Bhatnagar (Eds.): BDA 2012, LNCS 7678, pp. Springer-Verlag Berlin Heidelberg 42-61, 2012. 
[12] ISO/IEC JTC 1. Information technology Big data, Preliminary Report 2014. ISO/IEC 2015

[13] Curino, C., Jones, E.P.C., Popa, R.A., Malviya, N., Wu, E., Madden, S., Balakrishnan, H., Zeldovich, N.: Realtional Cloud: A Database-as-aService for the Cloud. In: Proceedings of Conference on Innovative Data Systems Research, CIDR- 2011.

[14] A. Ferandez, Sara del R, V. opez, A. Bawakid, Maria J. del Jesus, J. M. Benitez, and F. Herrera. "Big Data with Cloud Computing: an insight on the computing environment, MapReduce, and programming frameworks". doi: 10.1002/widm.1134. WIREs Data Mining Knowl Discov, 4:380-409, 2014.

[15] K. Shim, SK. Cha, L. Chen, Han W-S, D. Srivastava, K. Tanaka, H. Yu, $\mathrm{X}$. Zhou. Data management challenges and opportunities in cloud computing. In: 17th International Conference on Database Systems for Advanced Applications (DASFAA'2012). Berlin/ Heidelberg: Springer 323; 2012. https://doi.org/10.1007/978-3-642-29035-0_30.

[16] K. Kambatla, G. Kollias, V. Kumar, A. Grama. Trends in big data analytics. J Parallel Distrib, 74:2561-2573, 2014. https://doi.org/10.1016/j.jpdc.2014.01.003

[17] S. Ghemawat, H. Gobioff, S.-T. Leung, The google file system, in: Proceedings of the 9th ACM Symposium on Operating Systems Principles (SOSP 2003), ACM, New York, USA, pp. 29-43, 2003. https://doi.org/10.1145/945445.945450. 